\title{
Does Economic Freedom Affect the Production Frontier? A Semiparametric Approach with Panel Data
}

Fan Zhang

Ripon College, ZhangF@Ripon.edu

Joshua C. Hall

West Virginia University, jhall23@mail.wvu.edu

Feng Yao

West Virginia University, Feng.Yao@mail.wvu.edu

Follow this and additional works at: https://researchrepository.wvu.edu/econ_working-papers

Part of the Growth and Development Commons

\section{Digital Commons Citation}

Zhang, Fan; Hall, Joshua C.; and Yao, Feng, "Does Economic Freedom Affect the Production Frontier? A Semiparametric Approach with Panel Data" (2017). Economics Faculty Working Papers Series. 18.

https://researchrepository.wvu.edu/econ_working-papers/18 


\section{WestVirginiaUniversity.}

Department of Economics

Working Paper Series

\section{Does Economic Freedom Affect The Production Frontier? A Semiparametric Approach With Panel Data}

Fan Zhang

Joshua C. Hall

Feng Yao

Working Paper No. 17-27

This paper can be found at the College of Business and Economics Working Paper Series homepage: 


\title{
Does Economic Freedom Affect The Production Frontier? A Semiparametric Approach With Panel Data
}

\author{
Fan Zhang ${ }^{\mathrm{a}}$, Joshua Hall ${ }^{\mathrm{b}, *}$, Feng Yao ${ }^{\mathrm{b}, \mathrm{d}}$ \\ ${ }^{a}$ Business Management Program, Ripon College, Ripon, WI 54971, USA \\ ${ }^{b}$ Department of Economics, West Virginia University, Morgantown, WV 26505, USA \\ ${ }^{c}$ China Center for Special Economic Zone Research, Shenzhen University, Shenzhen, Guangdong 518060, China \\ ${ }^{d}$ School of Economics and Trade, Guangdong University of Foreign Studies, Guangzhou, Guangdong 510006, China
}

\begin{abstract}
This paper applies a multi-step semiparametric stochastic production frontier estimator proposed by Yao et al. (2017) to investigate the effects of economic freedom on the production frontier and technical efficiency. We allow output elasticities and technical efficiency to depend on the economic freedom variable, estimate a smooth coefficient stochastic production frontier, and compare with parametric alternatives, the Cobb-Douglas and translog estimates. Our results add to the literature on economic freedom and growth in three ways. First, our results highlight the flexibility of semiparametric approaches as we find the commonly used parametric approaches to be too restrictive in estimating the marginal productivity of inputs. Second, we find that the output elasticities of labor, human capital, and physical capital vary with the level of economic freedom. Third, our average efficiency estimates are at least $20 \%$ higher than those obtained from the parametric counterparts, suggesting that previous papers have mismeasured the impact of economic freedom on technical efficiency.
\end{abstract}

Keywords: Economic freedom, Technical efficiency, Semiparametric smooth coefficient model JEL Codes: C14, O43

\footnotetext{
* Corresponding author

Email addresses: zhangf@ripon.edu (Fan Zhang), Joshua.Hall@mail.wvu.edu (Joshua Hall), Feng.Yao@mail.wvu.edu (Feng Yao)
} 


\section{Introduction}

In recent decades, the creation of cross-country measures of economic and political institutions has led to a large literature on the effect of institutions on growth. One measure of economic institutions is the Economic Freedom of the World (EFW) index by Gwartney et al. (2015). The EFW index has been used as a measure of institutions in hundreds of studies in economics and related disciplines (Hall \& Lawson, 2014). By far the most frequent relationship of interest to economists has been the impact of institutions on growth. The very first major empirical paper using the EFW index was on this question (Easton \& Walker, 1997) and subsequent years have seen dozens of papers written on the economic freedom/growth relationship. Gwartney (2009) summarizes what is known about the relationship between economic freedom and growth in his presidential address to the Southern Economic Association. ${ }^{1}$

We investigate the mechanism through which economic freedom can affect economic performance, measured by a country's technical efficiency, or deviation from the production frontier. If information on price is available together with an appropriate behavioral assumption on cost minimization or profit maximization, then one can also consider allocative efficiency. For example, in the input selection case, allocative efficiency entails selecting the mix of inputs that produce a given output with given input prices at minimum costs. Allocative and technical efficiency combine to provide an overall economic efficiency measure. Since we utilize country level aggregated data, the behavioral assumption is not obvious. Thus, we measure economic performance with a country's technical efficiency. Different countries operate at different distances from the production frontier, and clearly efficiency can be influenced by institutional quality (Adkins et al., 2002). We expect that economic freedom can generally impact both the production frontier and efficiency, thus accuracy in estimating both will be crucial to assess a country's efficiency level. From a policy perspective, accuracy is important as policymakers should be better informed about the amount of technical inefficiency that exists in an economy and exactly how changes in institutional quality at different stages influence the marginal productivity of capital and labor as well as technical efficiency.

In this paper we add to this literature by applying a smooth coefficient stochastic frontier model to estimate the production frontier and therefore assess countries' efficiency. We believe that the impact of economic freedom on production frontier cannot be simply captured by entering it into production function linearly as a regular input or neutrally as assumed by much of the literature. The impact depends further, potentially nonlinearly, on how economic freedom affects output elasticities (marginal

\footnotetext{
${ }^{1}$ Some well-cited papers in this literature include Dawson (1998), Gwartney et al. (1999), Heckelman \& Stroup (2000), Carlsson \& Lundström (2002), Dawson (2003), De Haan et al. (2006), and Justesen (2008).
} 
products) of human capital, labor, and physical capital. ${ }^{2}$ First, increases in economic freedom improve the mobility of labor and capital across countries (Ashby, 2010; Azman-Saini et al., 2010; Nejad \& Young, 2016). For example, an increase in economic freedom for countries with low economic freedom would make physical capital, such as foreign direct investment, more accessible (Bengoa \& SanchezRobles, 2003; Kapuria-Foreman, 2007). Economic freedom thus alters opportunity costs between labor and capital and affects output elasticities. ${ }^{3}$ Second, economic freedom also reduces transactions costs, which improves productivity in terms of output elasticity (Klein \& Luu, 2003). Clearly, the impacts of economic freedom can be highly nonlinear, both neutrally and non-neutrally. A country's economic freedom is not a typical input like labor, physical capital or human capital, thus we should naturally treat it as an auxiliary/environmental variable when assessing its impact. Specifically in terms of its effect on the frontier, unlike regular inputs, economic freedom level can have a facilitating impact, thereby shifting the frontier neutrally, but it can also influence non-neutrally by affecting the productivity of regular inputs as argued above. To ignore this effect of economic freedom on the productivity of inputs could lead to a mismeasurement of the amount of technical inefficiency in an economy. Our semiparametric model is perfect for capturing both the neutral and non-neutral effects, which are purely nonparametric.

The effects of economic freedom on output elasticities are largely ignored in the empirical literature on economic freedom and growth. While a handful of studies employ a stochastic production frontier approach to this question, they do not investigate the effect of output elasticities. Instead, their focus is largely on how economic freedom affects technical efficiency. For example, Adkins et al. (2002) investigate the effects of economic freedom on the production frontier and find that more economic freedom in a country leads to decreased inefficiency. They do not, however, address the effect of economic freedom on output elasticities on the frontier. Clearly, a misspecified frontier can lead to misleading technical efficiency estimates and therefore the policy importance of economic freedom relative to inputs such as capital and labor. Similarly, while Klein \& Luu (2003) find that increased economic freedom reduces technical inefficiency, they do not allow the elasticities of human or physical capital to vary with the level of institutional quality and henceforth fail to recognize the non-neutral effect of institutional changes on productivity.

To address this hole in the literature we adopt the semiparametric smooth coefficient model pioneered by Li et al. (2002) and recently extended by Yao et al. (2017). This approach allows us to explicitly explore both the neutral effect of economic freedom (the shifting of the production frontier neutrally by economic freedom) and the non-neutral effect (the shifting of the production frontier through changing

\footnotetext{
${ }^{2}$ In this respect, our work is similar to that of Hall et al. (2010), who find in a cross-section that the marginal product of labor and capital varies with the institutional quality of a country.

${ }^{3}$ Throughout the paper we will use output elasticity and marginal product interchangeably.
} 
output elasticities). We also allow the efficiency distribution to depend on economic freedom through a scaling function on efficiency, thus the conditional mean and variance of the efficiency depend on economic freedom. This is in contrast with the approaches so far in the literature, which arbitrarily allow only the conditional mean to depend on economic freedom, which can result in biased estimates. Thus, we believe that our efficiency estimates are robust to potential misspecification from both the frontier and efficiency distribution. We apply the multi-step procedure developed by Yao et al. (2017) and estimate a smooth coefficient stochastic production frontier with a country level panel data from 1980 to 2010 observed at 5 -year increments. We do so in order to estimate the effect of economic freedom $(E F)$ on both the production frontiers and technical efficiencies of countries.

Contrary to Hall et al. (2010), we find that the marginal product of human capital and labor is decreasing when countries have an intermediate level of economic freedom. ${ }^{4}$ We find, however, that increases in economic freedom improve the marginal product of physical capital when a country has a moderate economic freedom but negatively affects marginal product of physical capital when economic freedom is low or high. The result shows that for many countries, though the neutral impact is positive and decreasing with economic freedom, higher economic freedom results in an overall outward shift in the production frontier. For example, if China in 2010 had economic freedom at the level of the United States, its production frontier would shift upward by over 20 percent. We compare the estimates for our semiparametric model with three parametric counterparts (Cobb-Douglas, translog, and restricted translog) and perform a model specification test. The tests suggest that the semiparametric model is more appropriate for modeling production frontiers. Failure to account for the potentially delicate nonlinear impact of economic freedom to the frontier results in misleading efficiency levels. Empirically, the average efficiency estimates from our semiparametric model are much higher, at least $20 \%$ higher, than those from parametric models.

The remainder of this article is organized as following. Section 2 introduces our methodology and model specifications. Section 3 describes the nature of variables and data sources. Section 4 discusses empirical results, illustrating the smooth varying coefficients of stochastic production frontiers and the distribution of technical efficiency. Section 5 provides a robustness check with an alternative measure of economic freedom and section 6 concludes.

\section{Methodology and Model Specification}

Adkins et al. (2002) investigate the effects of economic freedom on production frontier and technical

\footnotetext{
${ }^{4}$ Our empirical approach, however, is different from theirs and thus our results are not directly comparable.
} 
efficiency. However, using a parametric Cobb-Douglas production function with composite error, they only examine the neutral and linear effect of economic freedom on production frontier but ignore the non-neutral effects of economic freedom on the marginal productivity of inputs. Klein \& Luu (2003) also employ a parametric Cobb-Douglas production function approach. The dependence of the efficiency term on economic freedom is through representing the conditional mean as a linear function of determinant variables, including economic freedom. Note that the conditional variance of efficiency is modeled as a constant. This modeling strategy is considered to be arbitrary (Parmeter \& Kumbhakar, 2014, p. 55). For example, if the goal is to study how economic freedom affects effciency, there is no particular reason why it should be assumed to exert influence through conditional mean but not variance.

We follow Yao et al. (2017) and consider a semiparametric smooth coefficient stochastic production frontier for panel data. Specifically, for $i=1, \cdots, n$ and $t=1, \cdots, T$,

$$
\begin{aligned}
Y_{i t} & =\alpha\left(E F_{i t}\right)+\beta_{H}\left(E F_{i t}\right) \operatorname{Ln}\left(H_{i t}\right)+\beta_{L}\left(E F_{i t}\right) \operatorname{Ln}\left(L_{i t}\right)+\beta_{K}\left(E F_{i t}\right) \operatorname{Ln}\left(K_{i t}\right)+\epsilon_{i t} \\
& =\left(1, X_{i t}^{\prime}\right)\left(\alpha\left(E F_{i t}\right), \beta\left(E F_{i t}\right)^{\prime}\right)^{\prime}+\epsilon_{i t} \\
& =\left(1, X_{i t}^{\prime}\right) \delta\left(E F_{i t}\right)+\epsilon_{i t}
\end{aligned}
$$

where $Y_{i t}$ is the logarithm of output, $X_{i t}=\left(\operatorname{Ln}\left(H_{i t}\right), \operatorname{Ln}\left(L_{i t}\right), \operatorname{Ln}\left(K_{i t}\right)\right)^{\prime}$ represent the logarithm of traditional inputs, including human capital, labor and capital, and $\delta\left(E F_{i t}\right)=\left(\alpha\left(E F_{i t}\right), \beta\left(E F_{i t}\right)^{\prime}\right)^{\prime}$, where $\beta\left(E F_{i t}\right)=\left(\beta_{H}\left(E F_{i t}\right), \beta_{L}\left(E F_{i t}\right), \beta_{K}\left(E F_{i t}\right)\right)^{\prime}$, is a vector of unknown smooth functions of exogenous environmental variable, the economic freedom. The composite error is $\epsilon_{i t}=v_{i t}-u_{i t}$, where we specify a two-sided error $v_{i t} \sim$ i.i.d.N $\left(0, \sigma_{v}^{2}\right)$ representing random noise which independent of $E F_{i t}, X_{i t}$, and $u_{i t} ; u_{i t}=u_{i} g\left(E F_{i t} ; \eta\right)$ for a one-sided error $u_{i}$, scaled by a nonnegative function $g\left(E F_{i t} ; \eta\right)$ known up to parameter $\eta$, capturing inefficiency. We consider $u_{i} \sim$ i.i.d. $\left|N\left(0, \sigma_{u}^{2}\right)\right|$ and independent of $E F_{i t}$ and $X_{i t} . E F_{i t}$ enters inefficiency term through the scaling function $g(\cdot)$ to affect the distribution of $\epsilon_{i t}$. For $E F_{i}=\left(E F_{i 1}, \cdots, E F_{i T}\right)^{\prime}$ and $\epsilon_{i}=\left(\epsilon_{i 1}, \cdots, \epsilon_{i T}\right)^{\prime}$, we denote the conditional density of $\epsilon_{i}$ given $E F_{i}$ by $h\left(\epsilon_{i} ; E F_{i}, \theta_{0}\right)$, where $\theta_{0}=\left(\sigma_{u}^{2}, \sigma_{v}^{2}, \eta\right)^{\prime}$ denote the true parameters. Thus with above distribution specifications, $E\left(\epsilon_{i t} \mid E F_{i t}\right)=-\mu\left(E F_{i t} ; \theta_{0}\right)=-\sqrt{\frac{2}{\pi}} \sigma_{u} g\left(E F_{i t}, \eta\right)$ and $V\left(\epsilon_{i t} \mid E F_{i t}\right)=\sigma_{v}^{2}+\frac{\pi-2}{\pi} \sigma_{u}^{2} g^{2}\left(E F_{i t}, \eta\right)$. We employ a Gaussian kernel function $K(u)=e^{-u^{2} / 2} / \sqrt{2 \pi}$ and data driven least square cross validation method to find the optimal bandwidth for our dataset.

Since the seminar work of Aigner et al. (1977) and Meeusen \& Van Den Broeck (1977), the stochastic frontier (SF) approach as a tool to model and estimate efficiency has grown exponentially (see Kumbhakar et al. (2015) for extensive reviews and applications). SF models are popular among practitioners due to the fact that these models accommodate stochastic noise as an integral part of the production technology and can separate noise from inefficiency. Furthermore, one can easily perform statistical tests on many 
economic hypotheses of interest. However, restrictive assumptions typically are made on either the production frontier function and/or the distributional assumptions, with respect to inefficiency and the noise terms. For example, the SF model introduced by Aigner et al. (1977) and Meeusen \& Van Den Broeck (1977) uses a parametric frontier along with a composite error term in which the one-sided inefficiency term follows a particular distribution (half-normal for example), while the noise term follows a normal distribution.

With panel data, one can relax the distribution assumption on the inefficiency term (see Schmidt \& Sickles (1984), Cornwell et al. (1990) and Lee \& Schmidt (1993), Horrace \& Parmeter (2011) and Parmeter et al. (2017) for different approaches). However, flexibility in modeling the frontier is still limited to a known parametric functional form such as Cobb-Douglas or translog. Even with a correctly specified distribution for the composite errors, an incorrectly specified frontier function can still lead to misleading conclusion regarding inefficiency levels, returns to scale, technical change, etc. On the other hand, maintaining the distribution structure in Aigner et al. (1977) and Fan et al. (1996), MartinsFilho \& Yao (2015) investigate a nonparametric frontier model and examine properties of the estimators. Kumbhakar et al. (2007), and Park et al. (2015) model and estimate the frontier and all parameters of the distribution of the composite error as smooth functions of the inputs. A common feature of the these methods is that the frontier is fully nonparametric, although the rate of convergence of the proposed frontier estimator is rather slow especially when the number of inputs (conditioning variables) is large. It is the well-known curse of dimensionality problem afflicting multivariate kernel based nonparametric estimation. Since it is common to have a large number of variables in frontier models, the accuracy of the asymptotic approximation can be rather poor.

In this paper, we utilize the smooth coefficient frontier model introduced in Yao et al. (2017). The frontier function takes a more flexible functional form, i.e., $\alpha\left(E F_{i t}\right)+X_{i t}^{\prime} \beta\left(E F_{i t}\right)$, instead of just a linear or a semiparametric partially linear form. The sample size required for estimation is not as demanding as a fully nonparametric frontier model, and therefore likely to be useful to the applied researchers. Clearly, the frontier can be shifted neutrally by economic freedom via $\alpha(E F)$, and also non-neutrally through $\beta(E F)$. The semiparametric frontier model proposed in this article is different from the standard smooth coefficient regression model ( $\mathrm{Li}$ et al., 2002; Cai \& Li, 2008) because the conditional mean of the composite error is not zero due to the presence of the one-sided inefficiency term. We assume that the inefficiency and noise term follow the half-normal and normal distributions which depends on economic freedom. To capture the dependence, we allow that $E F$ enters inefficiency term through the scaling function $g(\cdot)$ to affect the distribution of the efficiency, thus, the conditional mean and variance of the inefficiency term is a function of EF, known up to certain parameters. This is in contrast to Adkins et al. (2002), 
who allow EF to arbitrarily impact only the mean, but not the variance, of inefficiency. Thus, we allow the inefficiency to vary across individual and time through its dependence on EF. We note that it is important to determine the level of inefficiency and also to understand how the inefficiency is affected by $\mathrm{EF}$. Ignoring the effect of EF in the composite error term, especially in the one-sided inefficiency term, can cause biased estimates of the frontier function and technical inefficiency level. This could, in turn, potentially lead to incorrect policy inferences.

We utilize a multi-step estimation procedure to consistently estimate the semiparametric frontier function (See Yao et al. $\left.(2017)^{5}\right)$. Since $E\left(\epsilon_{i t} \mid E F_{i t}\right) \neq 0$, the standard smooth varying coefficient estimation as in Li et al. (2002) can not be applied directly. Instead, subtracting conditional mean of Equation (1) on both sides, we have

$$
Y_{i t}-E\left(Y_{i t} \mid E F_{i t}\right)=\left(X_{i t}-E\left(X_{i t} \mid E F_{i t}\right)\right)^{\prime} \beta\left(E F_{i t}\right)+\mu\left(E F_{i t} ; \theta_{0}\right)+\epsilon_{i t},
$$

then we estimate $\hat{\delta}\left(E F_{i t}\right)$ and $\hat{\theta}$ with the following steps.

First, let $\tilde{\epsilon}_{i t}=\epsilon_{i t}+\mu\left(E F_{i t} ; \theta_{0}\right)$, then $E\left(\tilde{\epsilon}_{i t} \mid E F_{i t}\right)=0$. From Equation (2), we construct $\tilde{y}_{i t}=$ $Y_{i t}-\hat{E}\left(Y_{i t} \mid E F_{i t}\right), \tilde{X}_{i t}=X_{i t}-\hat{E}\left(X_{i t} \mid E F_{i t}\right)$, where $\hat{E}\left(Y_{i t} \mid E F_{i t}\right)$ and $\hat{E}\left(X_{i t} \mid E F_{i t}\right)$ are local linear estimates of conditional mean of $Y_{i t}$ and $X_{i t}$, respectively, evaluated at $E F_{i t}$. Then, Equation (2) transforms into,

$$
\tilde{y}_{i t}=\tilde{X}_{i t}^{\prime} \beta\left(E F_{i t}\right)+\tilde{\epsilon}_{i t},
$$

and we apply standard smooth varying coefficient estimation (see Li et al. (2002)) on Equation (3) to obtain consistent estimator $\check{\beta}(E F)=\left(\check{\beta}_{L}(E F), \breve{\beta}_{H}(E F), \check{\beta}_{K}(E F)\right)^{\prime}=\hat{b}_{0}$, where $\hat{b}_{0}=\left(\hat{b}_{0 H}, \hat{b}_{0 L}, \hat{b}_{0 K}\right)^{\prime}$, $\hat{b}_{1}=\left(\hat{b}_{1 H}^{\prime}, \hat{b}_{1 L}^{\prime}, \hat{b}_{1 K}^{\prime}\right)^{\prime}, \hat{b}=\left(\hat{b}_{0}^{\prime}, \hat{b}_{1}^{\prime}\right)^{\prime}$, such that

$$
\hat{b}=\underset{b}{\operatorname{argmin}} \sum_{i=1}^{n} \sum_{t=1}^{T} K\left(\frac{E F_{i t}-E F}{h}\right)\left(\tilde{y}_{i t}-\tilde{W}_{i t}^{\prime} b\right)^{2},
$$

where $\tilde{W}_{i t}=\left[\begin{array}{l}\tilde{X}_{i t} \\ \tilde{X}_{i t} \otimes\left(E F_{i t}-E F\right)\end{array}\right]$, and $\otimes$ denotes the Kronecker product.

Second, recall that $\mu\left(E F_{i t} ; \theta_{0}\right)$ is known up to the parameter $\theta_{0}$, we can construct $\hat{\epsilon}_{i t}(\theta)=\tilde{y}_{i t}-$ $\tilde{X}_{i t} \check{\beta}\left(E F_{i t}\right)-\mu\left(E F_{i t} ; \theta\right)$, and $\hat{\epsilon}_{i}(\theta)=\left\{\hat{\epsilon}_{i t}(\theta)\right\}_{t=1}^{T}$. We estimate $\theta$ by $\hat{\theta}$ via pseudo-likelihood estimation.

\footnotetext{
${ }^{5}$ Yao et al. (2017) propose a four-step semiparametric estimators, establish their consistency and asymptotic normality, and carry out a comprehensive Monte Carlo study.
} 
Following Pitt \& Lee (1981), we write the log-likelihood function as,

$$
\begin{aligned}
\operatorname{Ln} \prod_{i=1}^{n} h\left(\hat{\epsilon}_{i}(\theta) ; E F_{i}, \theta\right)= & C-\frac{n(T-1)}{2} \ln \sigma_{v}^{2}-\frac{1}{2} \sum_{i=1}^{n} \ln \left(\sigma_{v}^{2}+\sigma_{u}^{2} \sum_{t=1}^{T} g^{2}\left(E F_{i t} ; \eta\right)\right) \\
& +\sum_{i=1}^{n} \ln \left[1-\Phi\left(-\frac{\mu_{* i}}{\sigma_{* i}}\right)\right]+\frac{1}{2} \sum_{i=1}^{n}\left(\frac{\mu_{* i}}{\sigma_{* i}}\right)^{2}-\frac{\sum_{i=1}^{n} \sum_{t=1}^{T} \hat{\epsilon}_{i t}^{2}(\theta)}{2 \sigma_{v}^{2}}
\end{aligned}
$$

where $\sigma_{i}^{2}=\sigma_{v}^{2}+\sigma_{u}^{2} \sum_{t=1}^{T} g^{2}\left(E F_{i t} ; \eta\right), \lambda=\sigma_{u} / \sigma_{v}, \mu_{* i}=-\sigma_{u}^{2} \sum_{t=1}^{T} \epsilon_{i t} g\left(E F_{i t} ; \eta\right) / \sigma_{i}^{2}, \sigma_{* i}^{2}=\sigma_{u}^{2} \sigma_{v}^{2} / \sigma_{i}^{2}$, and $\sigma_{v}^{2}=\sigma_{i}^{2} /\left(1+\lambda^{2} \sum_{t=1}^{T} g^{2}\left(E F_{i t} ; \eta\right)\right)$, and $\phi(\cdot)$ and $\Phi(\cdot)$ refer to the PDF and CDF of a standard normal, respectively. Furthermore, we choose $g\left(E F_{i t} ; \eta\right)=e^{\eta E F_{i t}}$ in the application, $\eta$ can be interpreted as the semi-elasticity of expected inefficiency with respect to $E F_{i t}$.

Third, after $\hat{\theta}$ is obtained in the second step, $\mu\left(E F_{i t} ; \hat{\theta}\right)$ can be estimated. Adding $\mu\left(E F_{i t} ; \hat{\theta}\right)$ to both sides of Equation (1), we have

$$
Y_{i t}+\mu\left(E F_{i t} ; \hat{\theta}\right)=\left(1, X_{i t}^{\prime}\right) \delta\left(E F_{i t}\right)+\mu\left(E F_{i t} ; \hat{\theta}\right)+\epsilon_{i t},
$$

Again, since $E\left(\tilde{\epsilon}_{i t} \mid E F_{i t}\right)=0$, we estimate $\hat{\delta}\left(E F_{i t}\right)=\left(\hat{\alpha}\left(E F_{i t}\right), \hat{\beta}\left(E F_{i t}\right)^{\prime}\right)^{\prime}$ with the standard smooth varying coefficient estimation. Specifically, $\hat{\delta}(E F)=\hat{a}_{0}$, where $\hat{a}_{0}=\left(\hat{a}_{00}, \hat{a}_{0 H}, \hat{a}_{0 L}, \hat{a}_{0 K}\right)^{\prime}, \hat{a}_{1}=\left(\hat{a}_{10}^{\prime}, \hat{a}_{1 H}^{\prime}, \hat{a}_{1 L}^{\prime}, \hat{a}_{1 K}^{\prime}\right)^{\prime}$, $\hat{a}=\left(\hat{a}_{0}^{\prime}, \hat{a}_{1}^{\prime}\right)^{\prime}$, such that

$$
\hat{a}=\underset{a}{\operatorname{argmin}} \sum_{i=1}^{n} \sum_{t=1}^{T} K\left(\frac{E F_{i t}-E F}{h}\right)\left(\check{y}_{i t}-\tilde{Q}_{i t}^{\prime} a\right)^{2},
$$

where $\tilde{Q}_{i t}=\left[\begin{array}{l}\left(1, X_{i t}^{\prime}\right)^{\prime} \\ \left(1, X_{i t}^{\prime}\right)^{\prime} \otimes\left(E F_{i t}-E F\right)\end{array}\right]$ and $\check{y}_{i t}=Y_{i t}+\mu\left(E F_{i t} ; \hat{\theta}\right)$.

Finally, following Jondrow et al. (1982), we calculate observation specific technical inefficiencies for our semiparametric model. With proper modifications, we derive the conditional density of $u_{i t}$ given $\epsilon_{i t}$ and $E F_{i t}$ as

$$
f\left(u_{i t} \mid \epsilon_{i t}, E F_{i t}\right)=\left[1-\Phi\left(\epsilon_{i t} \frac{\sigma_{u} g_{i t}}{\sigma\left(E F_{i t}\right) \sigma_{v}}\right)\right]^{-1} \frac{1}{\sqrt{2 \pi}\left(\frac{\sigma_{v} \sigma_{u} g_{i t}}{\sigma\left(E F_{i t}\right)}\right)} \exp \left[-\frac{1}{\frac{2 \sigma_{v}^{2} \sigma_{u}^{2} g_{i t}^{2}}{\sigma^{2}\left(E F_{i t}\right)}}\left(u_{i t}+\frac{\epsilon_{i t} \sigma_{u}^{2} g_{i t}^{2}}{\sigma^{2}\left(E F_{i t}\right)}\right)^{2}\right]
$$

where $g_{i t}=g\left(E F_{i t} ; \eta\right)$, and $\sigma^{2}\left(E F_{i t}\right)=\sigma_{v}^{2}+\sigma_{u}^{2} g^{2}\left(E F_{i t}\right)$. We estimate technical efficiency as $T E_{i t}=$ $e^{-M\left(u_{i t} \mid \epsilon_{i t}, E F_{i t}\right)}$, where $M\left(u_{i t} \mid \epsilon_{i t}, E F_{i t}\right)=-\epsilon_{i t} \frac{\sigma_{u}^{2} g^{2}\left(E F_{i t} ; \eta\right)}{\sigma\left(E F_{i t}\right)}$ if $\epsilon_{i t} \leq 0$ and $M\left(u_{i} \mid \epsilon_{i t}, E F_{i t}\right)=0$ if $\epsilon_{i t}>0$.

We compare our semiparametric model with three benchmark models. The first is a Cobb-Douglas production function with composite error which is nested in Equation (1),

$$
Y_{i t}=\alpha_{0}+\alpha_{1} E F_{i t}+\alpha_{2} E F_{i t}^{2}+\beta_{H} \operatorname{Ln}\left(H_{i t}\right)+\beta_{L} \operatorname{Ln}\left(L_{i t}\right)+\beta_{K} \operatorname{Ln}\left(K_{i t}\right)+v_{i t}-u_{i} e^{\eta E F_{i t}},
$$


where we only allow economic freedom to shift the production frontier through the intercept term $\alpha\left(E F_{i t}\right)=\alpha_{0}+\alpha_{1} E F_{i t}+\alpha_{2} E F_{i t}^{2}$, a quadratic function to capture potential nonlinearity. All coefficients of $X_{i t}$ are assumed to be constants.

The second model is a translog model

$$
\begin{aligned}
Y_{i t}= & \alpha_{0}+\alpha_{1} E F_{i t}+\alpha_{2} E F_{i t}^{2}+\beta_{1 H} \operatorname{Ln}\left(H_{i t}\right)+\beta_{2 H} L^{2}\left(H_{i t}\right)+\beta_{1 L} \operatorname{Ln}\left(L_{i t}\right) \\
& +\beta_{2 L} \operatorname{Ln}^{2}\left(L_{i t}\right)+\beta_{1 K} \operatorname{Ln}\left(K_{i t}\right)+\beta_{2 K} \operatorname{Ln}^{2}\left(K_{i t}\right)+\beta_{E F H} E F_{i t} \operatorname{Ln}\left(H_{i t}\right) \\
& +\beta_{E F L} E F_{i t} \operatorname{Ln}\left(L_{i t}\right)+\beta_{E F K} E F_{i t} \operatorname{Ln}\left(K_{i t}\right)+\beta_{H L} \operatorname{Ln}\left(H_{i t}\right) \operatorname{Ln}\left(L_{i t}\right) \\
& +\beta_{H K} \operatorname{Ln}\left(H_{i t}\right) \operatorname{Ln}\left(K_{i t}\right)+\beta_{L K} \operatorname{Ln}\left(L_{i t}\right) \operatorname{Ln}\left(K_{i t}\right)+v_{i t}-u_{i} e^{\eta E F_{i t}}
\end{aligned}
$$

Due to the presence of square and cross products of $X_{i t}$, it is not nested in Equation (1), but it imposes no priori restrictions on substitution possibilities among input variables,

In the third benchmark, we restrict the translog production model such that the coefficients of $L n^{2}\left(H_{i t}\right), L n^{2}\left(L_{i t}\right), L n^{2}\left(K_{i t}\right), \operatorname{Ln}\left(L_{i t}\right) \operatorname{Ln}\left(K_{i t}\right), \operatorname{Ln}\left(L_{i t}\right) \operatorname{Ln}\left(H_{i t}\right)$, and $\operatorname{Ln}\left(H_{i t}\right) \operatorname{Ln}\left(K_{i t}\right)$ are jointly equal to zero, which makes it nested in Equation (1). After removing those terms, we estimate restricted translog model as,

$$
\begin{aligned}
Y_{i t}= & \alpha_{0}+\alpha_{1} E F_{i t}+\alpha_{2} E F_{i t}^{2}+\beta_{1 H} \operatorname{Ln}\left(H_{i t}\right)+\beta_{1 L} \operatorname{Ln}\left(L_{i t}\right)+\beta_{1 K} \operatorname{Ln}\left(K_{i t}\right) \\
& +\beta_{E F H} E F_{i t} \operatorname{Ln}\left(H_{i t}\right)+\beta_{E F L} E F_{i t} \operatorname{Ln}\left(L_{i t}\right)+\beta_{E F K} E F_{i t} \operatorname{Ln}\left(K_{i t}\right)+v_{i t}-u_{i} e^{\eta E F_{i t}}
\end{aligned}
$$

\section{Data Descriptions}

We use the country-level data from the Penn World Table $(P W T)$ and Economic Freedom of the World: 2015 Annual Report by Gwartney et al. (2015) to investigate the effects of economic freedom on a country's production frontier and technical efficiency. Our dataset consists of 440 observations for 110 countries from 1990 to 2010 observed at 5-year increments. ${ }^{6}$ A complete list of countries and their respective economic freedom as of 2010 are presented in Table 1. The EFW index is based on a $0-10$ scale, with higher scores representing higher levels of economic freedom.

We employ the Penn World Table because it is the most comprehensive country-level aggregated data comprised of human capital per capita, labor, and physical capital. The 8.1 version of the Penn World Table provides output-side real GDP in million of 2005 US dollars for different countries over time, which facilitates comparison of economic productivity across a large number of countries. The combined data

\footnotetext{
${ }^{6}$ We look at only five-year increments for two reasons. First, institutions change slowly and thus 5-year increments is standard in the economic freedom/growth literature. Second, the EFW index only reports at 5-year intervals from 1990 to 2000 .
} 
set enables us to estimate production frontiers and technical efficiency, and to investigate the effects of changing economic freedom on production frontiers.

Our dependent variable $Y$ is the logarithm of output-side real GDP in millions of 2005 US dollars. Independent variables include the logarithm of human capital per capita $\operatorname{Ln}(H)$, the logarithm of labor force $\operatorname{Ln}(L)$, and the logarithm of real capital stock $\operatorname{Ln}(K)$, where $H$ is an index of human capital based on years of schooling and returns to education (see Psacharopoulos (1994) and Barro \& Lee (2013)), labor force $L$ is in millions of persons participated in employment, and real capital stock $K$ is in millions of 2005 US dollars. Additional descriptions of variables from the Penn World Table can be obtained in Feenstra et al. (2015).

Economic freedom of the world index $(E F W)$ is our primary variable of interest in this paper and we treat it as the "environmental" variable in our estimation of production functions. Based on our hypothesis, the effects of economic freedom on output are double-sided. Increases in economic freedom can reduce transaction costs for productive activities, make foreign capital more accessible and domestic capital more productive, and improve the return on education, all of which boost productivity. However, on the other hand, increases in economic freedom also relax governmental control of the population, which increases the migration of immigrants to countries with higher levels of economic freedom. While this is likely to increase the productivity of destination countries, it will lower output elasticity in the origin country.

We use the chain-linked EFW index $(E F W)$ to ensure comparability across time. $E F W$ measures the degree of economics freedom in five major areas: (1) size of government; (2) legal system and security of property rights; (3) access to sound money; (4) freedom to trade internationally; and (5) regulation. Each of these components are based on several variables. The rating of size of government, for instance, is based on four separate components, such as government consumption as a percentage of total consumption. Each component is put on a 0 to 10 scale and then aggregated up to an overall score for the entire country, which also varies from 0 to 10 . The detailed $E F W$ index structure can be obtained from Gwartney et al. (2015). Gwartney \& Lawson (2003) provides an overview of the history and creation of the index. The summary statistics for all the variables are presented in Table 2.

\section{Estimation Results}

The estimation results for our semiparametric smooth coefficient model are summarized in Table 3 Panel A, providing the mean values and 10th, 50th (median), and 90th percentile of our smooth coefficients of $\hat{\delta}(E F)=\left(\hat{\alpha}(E F), \hat{\beta}_{H}(E F), \hat{\beta}_{L}(E F), \hat{\beta}_{K}(E F)\right)^{\prime}$, as well as the parameter estimate $\hat{\theta}=\left(\hat{\sigma}_{u}^{2}, \hat{\sigma}_{v}^{2}, \hat{\eta}\right)^{\prime}$. Compared with benchmark models presented in Table 4 Panel A, our semiparametric estimates give 
a lower $\hat{\sigma}_{u}^{2}$ but a higher $\hat{\sigma}_{v}^{2}, 2.0241$ and .0357 , respectively. The Cobb-Douglas production frontier, translog frontier, and restricted translog frontier give relative higher estimates of $\hat{\sigma}_{u}^{2}$ and lower $\hat{\sigma}_{v}^{2}$, where $\left(\hat{\sigma}_{u}^{2}, \hat{\sigma}_{v}^{2}\right)=(2.6714, .0217),\left(\hat{\sigma}_{u}^{2}, \hat{\sigma}_{v}^{2}\right)=(2.8809, .0194)$, and $\left(\hat{\sigma}_{u}^{2}, \hat{\sigma}_{v}^{2}\right)=(3.2214, .0209)$, respectively. All estimates suggest a relatively small magnitude for the random noise relative to that of the efficiency term. With an estimated $\hat{\eta}$ of -.1383 , our semiparmetric model implies that increased economic freedom will increase technical efficiency $\left(T E_{i t}\right)$. The Cobb-Douglas, translog, and restricted translog models suggest an estimated $\hat{\eta}$ of -.1156 and -.0519 and -.0404 , respectively, confirming our sempiparametric estimate (with the same sign, though of different magnitudes).

The restricted translog production function assumes that the coefficients of $\operatorname{Ln}^{2}\left(H_{i t}\right), \operatorname{Ln}^{2}\left(L_{i t}\right)$, $\operatorname{Ln}^{2}\left(K_{i t}\right), \operatorname{Ln}\left(L_{i t}\right) \operatorname{Ln}\left(K_{i t}\right), \operatorname{Ln}\left(L_{i t}\right) \operatorname{Ln}\left(H_{i t}\right)$, and $\operatorname{Ln}\left(H_{i t}\right) \operatorname{Ln}\left(K_{i t}\right)$ are jointly equal to zero. To check its validity empirically, we perform a likelihood ratio test for the null of $\beta_{2 H}=\beta_{2 L}=\beta_{2 K}=\beta_{H L}=$ $\beta_{H K}=\beta_{L K}=0$ which gives us a test statistic of .0943, smaller than the critical value of 12.592 at the $5 \%$ significance level. Since we cannot reject the null hypothesis and the restricted translog is also nested in our semiparametric model, we focus on Cobb-Douglas and restricted translog models as parametric counterparts in the following analysis.

Since our semiparametric estimators are smooth functions of the environmental variable $E F$, we plot our coefficients $\left(\hat{\alpha}(E F), \hat{\beta}_{H}(E F), \hat{\beta}_{L}(E F), \hat{\beta}_{K}(E F)\right)^{\prime}$ and their $95 \%$ confidence intevals, which are based on the asymptotic results in Yao et al. (2017), against economic freedom of the world index in Figure 1. For comparison purposes, we superimpose the parametric counterpart estimates. As expected, our smooth coefficients are mostly positive and nonlinear across the entire range of the economic freedom index, and exhibit different patterns.

The upper-left panel in Figure 1 presents the neutral effects of economic freedom $\hat{\alpha}(E F)$ against its parametric counterparts. The neutral effects of economic freedom on production from our semiparametric estimates are decreasing with economic freedom, but much smaller than those from parametric estimates. The upper-right panel in Figure 1 describes the output elasticity of human capital (or marginal product of human capital). It shows a decreasing pattern in general but also suggests improved productivities from human capital when economic freedom is above 7.5 (approximately Japan in 2010). The 95\% confidence bounds of sempiparametric estimates contain most of its parametric counterparts for the output elasticity of human capital, but it is not the case for the neutral effect. It suggests that parametric models yield fairly reasonable estimates for the output elasticity of human capital, but quite likely misspecify the neutral effect.

The lower-left panel in Figure 1 plots the output elasticity of labor (or marginal product of labor). It demonstrates that the output elasticity of labor decreases as the economic freedom of the world index 
rises. However, output elasticity of labor decreases at a slower rate once economic freedom reaches 6.0 (China in 2010). Our semiparametric estimates are generally much lower than the parametric estimates. The output elasticity of capital in the lower-right panel exhibits an increasing pattern in general but at a lower rate when economic freedom reaches 6.0. Our results suggests higher output elasticity of capital under semiparametric specification than parametric counterparts. In both cases, the confidence intervals of our semiparametric estimates do not contain the parametric counterparts, suggesting the parametric models are likely misspecified. The returns to scale estimates suggested by our semiparametric model at 10th, 50th, and 90th percentiles are .9477, 1.1258, and 1.9209, respectively, with a mean of 1.2972 . In comparison, Cobb-Douglas and restricted translog models indicate returns to scale estimates of 1.5274 and 1.3367 , respectively.

Discrepancies between semiparametric and parametric estimates imply that the parametric approaches, which are very much likely to suffer from misspecification, overestimate the neutral effect of economic freedom, output elasticity of labor and underestimate output elasticity of capital, but deliver reasonable estimates of output elasticity of human capital.

Given the pattern exhibited in Figure 1 and the fact that $\operatorname{Ln}(K)$ 's magnitude is much larger than other inputs, we expect that economic freedom shifts the production frontier upward. For illustration, let's consider the case of China. In 2010, China had a chain-linked EF score of 6.07. Our semiparametric model suggests that if China had the economic freedom level of the United States (7.76), its production frontier would be shifted upward by $\$ 3,914,667$ millions of 2005 US dollar or $20.83 \%$ higher than its estimated 2010 outputs on the frontier, ceteris paribus. In comparison, the Cobb-Douglas suggests that the same increase in $E F$ will have a much smaller impact on the production frontier, with an upward shift of $\$ 56,328$ millions of 2005 US dollar (or .28\% higher than the estimated 2010 production frontier). The restricted translog model indicates a larger upward shift of $\$ 4,971,707$ millions of 2005 US dollar (or $32.44 \%$ higher) on the frontier.

Figure 2 presents kernel density estimates of composite error and technical efficiency for all three models. The left panel indicates that composite errors for all three models cluster around -0.5 which suggests majority of observations are not fully technically efficient on average $\left(E\left(\epsilon_{i t} \mid E F_{i t}\right)<0\right)$ and operates below production frontier. Moreover, the kernel density of composite error for semiparametric estimates is taller and more tightly centered around -0.5 , suggesting smaller composite error in absolute values and higher technical efficiency on average under semiparametric estimates than those of parametric counterparts, whose densities exhibit a fairly obvious negative skewness with larger magnitudes in absolute value.

The right panel of Figure 2 presents density estimates of technical efficiency for semiparametric and 
parametric estimates. The results are consistent with what is suggested in the left panel. Compared with parametric counterparts, the density of semiparametric technical efficiency is more tightly centered at a higher level, suggesting higher efficiencies under the semiparametric approach. The average and median technical efficiency are .6955 and .7046 for the semiparametric model, at least $20 \%$ higher than those from the parametric models, which are .5009 and .4744 for Cobb-Douglas, and .5699 and .5625 for translog. The results suggest that technical efficiencies are likely to be mismeasured in parametric models. Our results are consistent with Adkins et al. (2002) and Klein \& Luu (2003) in the sense that majority of observations are technically inefficient. However, our estimates of technical efficiency are smaller in absolute values. A direct comparison between our and their estimates may not be appropriate since they incorporate many other variables such as political rights and civil liberty in the estimation of technical efficiency. However, we conjecture that their estimates can be misleading, since they assume constant output elasticities which can either overestimate or underestimate the impact of economic freedom on the elasticities as demonstrated in Figure 1.

In Equation (1), economic freedom shifts production frontier directly via $\alpha\left(E F_{i t}\right)$ and indirectly through the output elasticities of input variables, $\beta_{H}\left(E F_{i t}\right), \beta_{L}\left(E F_{i t}\right)$, and $\beta_{K}\left(E F_{i t}\right)$. Economic freedom also affects efficiency through $g\left(E F_{i t} ; \eta\right)$. To given the audience of a more vivid picture, we follow Yao et al. (2017) to obtain partial effect of economic freedom on technical efficiency change from $\partial \ln \tilde{T E_{i t}} / \partial L C_{i t}=\eta\left\{\ln \tilde{T E_{i t}}\right\}$ where $\ln \tilde{T E_{i t}}=-u_{i} \exp \left(\eta L C_{i t}\right)$, and $\tilde{T E_{i t}}=\exp \left(-u_{i t}\right)$. Note that for $\tilde{T E} E_{i t}$, we use the actual estimated $u_{i t}$, with $u_{i}$ replaced by estimated mean value and $\eta$ by its estimate. We did not use the Jondrow et al. (1982) estimate $T E_{i t}$ discussed before, since it depends on the unknown composite error $\epsilon_{i t}$ term, whose estimate generates a fair amount of random fluctuations in the graphs. Thus, we plot the partial effect of economic freedom on the efficiency changes for all three estimates against economic freedom in the left panel of Figure 5. The partial effects are found to be positive for all three but decrease with higher levels of economic freedom. This suggests that technical efficiency increases with more economic freedom, but at a decreasing rate.

If one believes that the smooth varying coefficients should take a parametric form, then one naturally would like to perform a model specification test. If the parametric functional form is not rejected, then one could use it for simplicity. We perform a model specification test proposed by Yao et al. (2017) to test parametric models against our semiparametric model. Following the wild bootstrap procedure described in Yao et al. (2017), the test statistics $\hat{T}_{n}{ }^{7}$ for the null hypotheses of Cobb-Douglas and translog model specifications are 343.62 and and 142.7, respectively, and the boot-strapped $p$-values are zero under both

\footnotetext{
${ }^{7}$ Yao et al. (2017) propose a modified test for parametric frontier specification based on Li et al. (2002) and Li \& Racine (2010) for panel data framework and establish asymptotic properties for the test statistics $\hat{T}_{n}$. Please refer to Yao et al. (2017) for details.
} 
scenarios, strongly rejecting the parametric models. Consequently, to address the effects of economic freedom on technical efficiency, the two popular parametric frontier models, being too restrictive in their functional forms, are likely misspecified.

\section{Robustness Testing}

To probe the robustness of the empirical results from section 4, we employ the index of economic freedom (IEF) from the Heritage Foundation (Miller \& Kim, 2017) as our alternative measurement of economic freedom and replicate the analysis above. While the IEF is based on the same philosophical foundation as the EFW, it covers slightly different data and is scaled from 0-100 as compared to the 0-10 of the EFW. The index of economic freedom covers variables in 10 major areas, including business freedom, trade freedom, monetary freedom, government size and spending, fiscal freedom, property rights, investment freedom, financial freedom, freedom from corruption, and labor freedom. We match the index of economic freedom with our dataset to improve comparability with our earlier results. As of 2010, Singapore exhibits the highest IEF score of 86.1 whereas Zimbabwe has the lowest score of 21.4. Both measurements of economic freedom are highly correlated, with a correlation of .8364. The IEF scores as of 2010 are listed in Table 1 and summary statistics are presented in Table 2.

The smooth coefficient estimates using IEF as the "environmental" variable are presented in Table 3 Panel B. The smooth coefficient estimates of output elasticities have similar magnitudes and are generally comparable with the estimates obtained from using EFW as the environmental variable. For the parameter estimate $\hat{\theta}$, it provides estimates at a smaller magnitude, where $\left(\hat{\sigma}_{u}^{2}, \hat{\sigma}_{v}^{2}, \hat{\eta}\right)=(.2834, .0217,-.0056)$. With an estimated $\hat{\eta}$ of -.0056 using an alternative measurement of economic freedom, it further confirms that higher levels of economic freedom increase technical efficiency. The Maximum Likelihood Estimation results for parametric models are tabulated in Table 4 Panel B. Comparing with the smooth coefficient estimates using IEF, the Cobb-Douglas, translog, and restricted translog models provide much larger estimates of $\hat{\sigma}_{u}^{2}$, similar estimates of $\hat{\sigma}_{v}^{2}$, and lower estimates of $\hat{\eta}$, where $\left(\hat{\sigma}_{u}^{2}, \hat{\sigma}_{v}^{2}, \hat{\eta}\right)=(8.3085, .0214,-.2292)$, $\left(\hat{\sigma}_{u}^{2}, \hat{\sigma}_{v}^{2}, \hat{\eta}\right)=(4.1121, .0209,-.1855)$, and $\left(\hat{\sigma}_{u}^{2}, \hat{\sigma}_{v}^{2}, \hat{\eta}\right)=(6.7571, .0212,-.2165)$, respectively.

We also plot smooth coefficients using IEF as environmental variable and their $95 \%$ confidence bounds in Figure 3 to facilitate comparison. Parametric estimates from the Cobb-Douglas and restricted translog models are also superimposed. As expected, the smooth coefficients using IEF as the environmental variable demonstrated similar patters as smooth coefficients generated using EFW as the environmental variable.

The neutral effects of economic freedom presented in the upper-left panel of Figure 3 show a decreasing pattern as economic freedom increases. The neutral effects on the production are much smaller than 
those from its parametric counterparts. The smooth coefficient estimate of output elasticity of human capital described in the upper-right panel of Figure 3 indicates a decreasing pattern as economic freedom increases but it starts to increase when index of economic freedom score exceeds 70 . It is consistent with the observation of output elasticity of human capital obtained when using EFW as the environment variable, which starts to increase when economic freedom exceeds 7.5. A large portion of parametric estimates also fall into the $95 \%$ confidence interval, suggesting reasonable estimates of output elasticity of human capital from parametric models.

The output elasticity of labor is presented in the lower-left panel of Figure 3 while output elasticity of capital is presented in the lower-right panel. Smooth coefficient function of output elasticity of labor decreases in general with economic freedom. Parametric models suggest higher output elasticity of labor as a fairly large portion of parametric estimates is above the upper bound of the confidence interval. The output elasticity of capital shows an increasing pattern as economic freedom increases but at a slower rate once economic freedom reached 60 . This is also consistent with the observation made using EFW as the environmental variable, where the output elasticity of capital increases at a much slower rate once economic freedom reaches the threshold of 6.0. Parametric results indicate lower estimates of output elasticity of capital than our semiparameric estimate.

We also present the kernel density estimates of the composite error and technical efficiency using IEF as economic freedom in Figure 4. The results are similar to those indicated using EFW as the environmental variable. Composite errors from both semiparametric and parametric models clusters around -.45 but semiparametric estimates are more tightly centered around -.45. This indicates smaller composite error and higher technical efficiency on average for our semiparametric estimates. The kernel density of technical efficiency for semiparametric model is also more tightly centered at a higher level, suggesting higher efficiencies under the semiparametric specification. We also plot the efficiency changes for all three models in the right panel of Figure 5 using IEF as the environmental variable. We observe the same decreasing pattern for the partial effect of economic freedom as before, though the partial effect for the semiparametric model has a much smaller magnitude due to a reduced estimate of $\hat{\eta}$.

\section{Conclusion}

In this paper, we apply a multi-step semiparametric smooth coefficient stochastic production frontier estimator proposed by Yao et al. (2017) to investigate the effects of economic freedom on production frontier and technical efficiency. We contrast the semiparametric estimate with Cobb-Douglas and translog. Allowing the output elasticities and technical efficiency to depend on the environmental variable, economic freedom, we observe significant variation on output elasticities. A model specification test indicates 
that both Cobb-Douglas and translog production frontiers are likely to be misspecified.

Our results add to the literature on economic freedom and growth in three ways. First, our results highlight the importance of flexible modeling as parametric estimates of the marginal productivity of inputs are shown to be fairly restrictive. Parametric approaches overestimate the neutral effect of economic freedom and the output elasticity of labor, and underestimate the output elasticity of capital, relative to our semiparametric estimates. Second, our empirical average efficiency estimates are at least $20 \%$ higher than those obtained from the parametric counterparts. Third, we find that the output elasticities of labor, human capital, and physical capital vary with the level of economic freedom. In this way our results are similar to that of Hall et al. (2010), but more precise. Our results suggest that the output elasticities are mostly positive. Interestingly, increased economic freedom generally lowers the output elasticities or marginal products of human capital and labor but leads to improvements in the marginal product of capital.

Like the previous literature we find that economic freedom shifts the semiparametric stochastic production frontier upward and reduces technical inefficiency. Thus, higher economic freedom is favored for a country to improve its efficiency in general. However, we discover that economic freedom positively impacts the frontier mainly through the non-neutral effect on the output elasticity of capital. Thus, on the policy front, countries with a higher capital to labor ratio are especially advised to improve its economic freedom, if the policy goal is to be as efficient as possible with its inputs.

\section{References}

Adkins, L. C., Moomaw, R. L., \& Savvides, A. (2002). Institutions, freedom, and technical efficiency. Southern Economic Journal, 69, 92-108.

Aigner, D., Lovell, C. A. K., \& Schmidt, P. (1977). Formulation and estimation of stochastic frontiers production function models. Journal of Econometrics, 6, 21-37.

Ashby, N. J. (2010). Freedom and international migration. Southern Economic Journal, 77, 49-62.

Azman-Saini, W. N. W., Baharumshah, A. Z., \& Law, S. H. (2010). Foreign direct investment, economic freedom and economic growth: International evidence. Economic Modelling, 27, 1079-1089.

Barro, R. J., \& Lee, J. W. (2013). A new data set of educational attainment in the world, 1950-2010. Journal of Development Economics, 104, 184-198.

Bengoa, M., \& Sanchez-Robles, B. (2003). Foreign direct investment, economic freedom and growth: new evidence from Latin America. European Journal of Political Economy, 19, 529-545. 
Cai, Z., \& Li, Q. (2008). Nonparametric estimation of varying coefficient dynamic panel data models. Econometric Thoery, 24, 1321-1342.

Carlsson, F., \& Lundström, S. (2002). Economic freedom and growth: Decomposing the effects. Public choice, 112, 335-344.

Cornwell, C., Schmidt, P., \& Sickles, R. C. (1990). Production frontiers with cross-sectional and timeseries variation in efficiency levels. Journal of Econometrics, 46, 185-200.

Dawson, J. W. (1998). Institutions, investment, and growth: New cross-country and panel data evidence. Economic inquiry, 36, 603-619.

Dawson, J. W. (2003). Causality in the freedom-growth relationship. European Journal of Political Economy, 19, 479-495.

De Haan, J., Lundström, S., \& Sturm, J.-E. (2006). Market-oriented institutions and policies and economic growth: A critical survey. Journal of Economic Surveys, 20, 157-191.

Easton, S. T., \& Walker, M. A. (1997). Income, growth, and economic freedom. American Economic Review, 87, 328-332.

Fan, Y., Li, Q., \& Weersink, A. (1996). Semiparametric estimation of stochastic production frontier models. Journal of Business $\& 3$ Economic Statistics, 14, 460-468.

Feenstra, R. C., Inklaar, R., \& Timmer, M. P. (2015). The next generation of the Penn World Table. American Economic Review, 105, 3150-3182.

Gwartney, J. (2009). Institutions, economic freedom, and cross-country differences in performance. Southern Economic Journal, 75, 937.

Gwartney, J., \& Lawson, R. (2003). The concept and measurement of economic freedom. European Journal of Political Economy, 19, 405-430.

Gwartney, J., Lawson, R., \& Hall, J. (2015). Economic Freedom of the World: 2015 Annual Report. Fraser Institute.

Gwartney, J. D., Lawson, R. A., \& Holcombe, R. G. (1999). Economic freedom and the environment for economic growth. Journal of Institutional and Theoretical Economics, 155, 643-663.

Hall, J. C., \& Lawson, R. A. (2014). Economic freedom of the world: An accounting of the literature. Contemporary Economic Policy, 32, 1-19. 
Hall, J. C., Sobel, R. S., \& Crowley, G. R. (2010). Institutions, capital, and growth. Southern Economic Journal, 777, 385-405.

Heckelman, J. C., \& Stroup, M. D. (2000). Which economic freedoms contribute to growth? Kyklos, 53, $527-544$.

Horrace, W. C., \& Parmeter, C. F. (2011). Semiparametric deconvolution with unknown error variance. Journal of Productivity Analysis, 35, 129-141.

Jondrow, J., Knox, C. A., \& Schmidt, P. (1982). On the estimation of technical inefficiency in the stochastic frontier production function model. Journal of Econometrics, 19, 233-238.

Justesen, M. K. (2008). The effect of economic freedom on growth revisited: new evidence on causality from a panel of countries 1970-1999. European Journal of Political Economy, 24, 642-660.

Kapuria-Foreman, V. (2007). Economic freedom and foreign direct investment in developing countries. Journal of Developing Areas, 41, 143-154.

Klein, P. G., \& Luu, H. (2003). Politics and productivity. Economic Inquiry, 41, 433-447.

Kumbhakar, S. C., Park, B. U., Simar, L., \& Tsionas, E. (2007). Nonparametric stochastic frontiers: A local maximum likelihood approach. Journal of Econometrics, 137, 1-27.

Kumbhakar, S. C., Wang, H.-J., \& Horncastle, A. P. (2015). A Practitioner's Guide to Stochastic Frontier Analysis Using Stata. Cambridge University Press.

Lee, Y., \& Schmidt, P. (1993). A production frontier model with flexible temporal variation in technical efficiency. In in L. H. Fried \{\&\} S. Schmidt, eds, 'The Measurement of Productive Efficiency'. Oxford, United Kingdom: Oxford University Press.

Li, Q., Huang, C. J., Li, D., \& Fu, T. (2002). Semiparametric smooth coefficient models. Journal of Business and Economic Statistics, 20, 412-422.

Li, Q., \& Racine, J. S. (2010). Smooth varying-coefficient estimation and inference for qualitative and quantitative data. Econometric Theory, 26, 1607-1637.

Martins-Filho, C., \& Yao, F. (2015). Nonparametric stochastic frontier estimation via profile likelihood. Econometric Reviews, 34, 413-451.

Miller, T., \& Kim, A. (2017). 2017 Index of Economic Freedom. Heritage Foundation. 
Meeusen, W., \& Van Den Broeck, J. (1977). Efficiency estimation from Cobb-Douglas production functions with composed error. International Economic Review, 18, 435-444.

Nejad, M. N., \& Young, A. T. (2016). European Journal of Political Economy, 45, 71-84.

Park, B. U., Simar, L., \& Zelenyuk, V. (2015). Categorical data in local maximum likelihood: theory and applications to productivity analysis. Journal of Productivity Analysis, 43, 199-214.

Parmeter, C. F., \& Kumbhakar, S. C. (2014). Efficiency Analysis: A Primer on Recent Advances. Foundations and Trends® in Econometrics, 7, 191-385.

Parmeter, C. F., Wang, H.-J., \& Kumbhakar, S. C. (2017). Nonparametric estimation of the determinants of inefficiency.. Journal of Productivity Analysis, 47, 205-221.

Pitt, M. M., \& Lee, L.-F. (1981). The measurement and sources of technical inefficiency in the Indonesian weaving industry. Journal of Development Economics, 9, 43-64.

Psacharopoulos, G. (1994). Returns to investment in education: A global update. World Development, 22, 1325-1334.

Schmidt, P., \& Sickles, R. C. (1984). Production frontiers and panel data. Journal of Business \& Economic Statistics, 2, 367-374.

Yao, F., Zhang, F., \& Kumbhakar, S. C. (2017). Semiparametric smooth coefficient stochastic frontier model with panel data. Journal of Business 83 Economic Statistics, forthcoming (http://dx.doi.org/10.1080/07350015.2017.1390467). 


\section{Appendix: Tables and Figures}

Table 1: List of Countries and Economic Freedom as of 2010

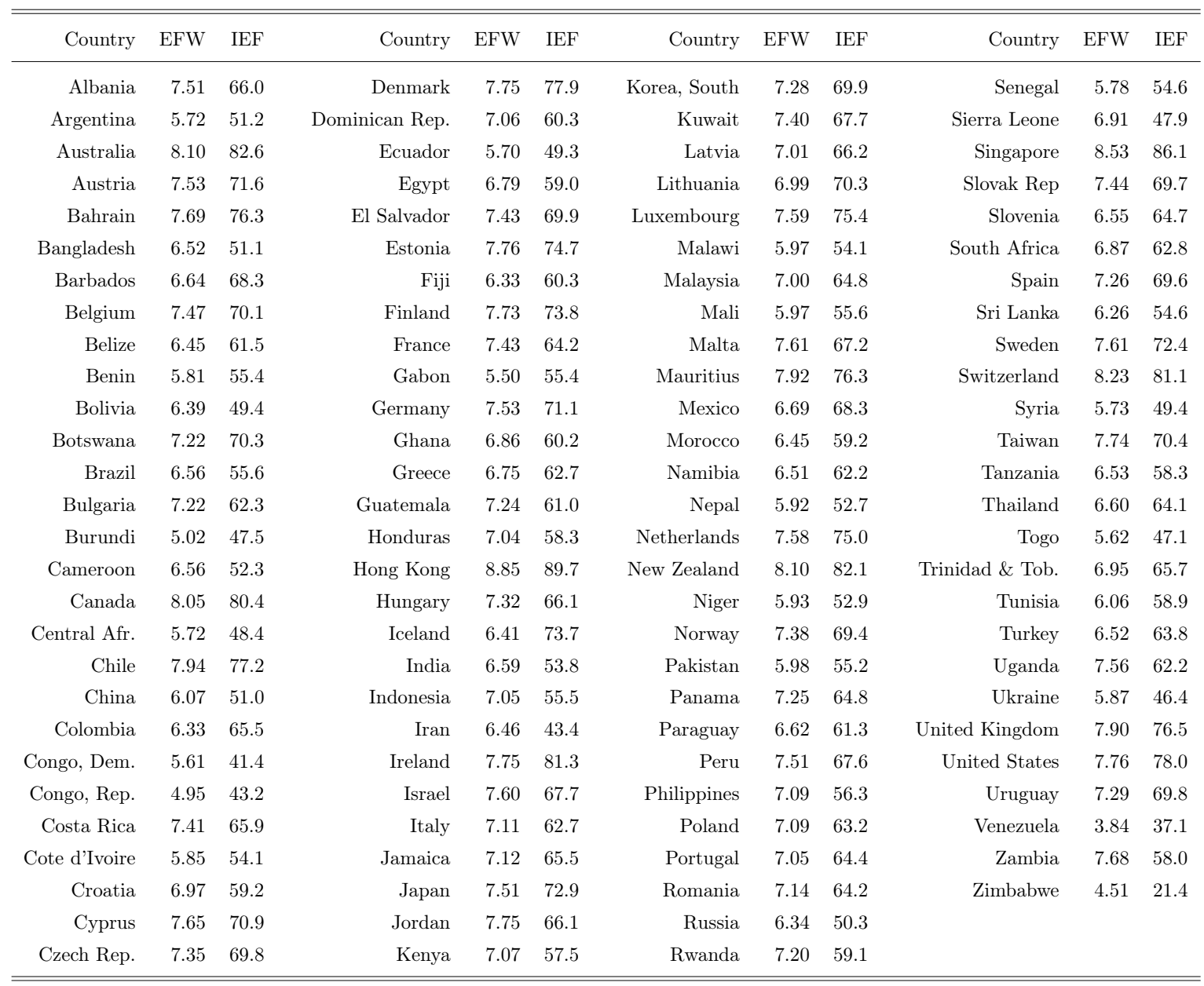


Table 2: Summary Statistics

\begin{tabular}{llrrrrr}
\hline \hline Symbol & Variable Description & Mean & Std. & Min. & Max. & Bandwidth \\
\hline $\operatorname{Ln}(Y)$ & Log of Output-Side Real GDP & 11.3531 & 1.9074 & 7.0998 & 16.3799 & - \\
$\operatorname{Ln}(H)$ & Log of Human Capital & .8947 & .2442 & .1397 & 1.2864 & - \\
$\operatorname{Ln}(L)$ & Log of Labor Force & 1.5453 & 1.6410 & -2.8134 & 6.6611 & - \\
$\operatorname{Ln}(K)$ & Log of Capital Stock & 12.2795 & 2.0745 & 6.9201 & 17.5224 & - \\
$E F W$ & Economic Freedom of the World & 6.6790 & 1.0913 & 2.9707 & 9.1509 & .7891 \\
$I E F$ & Index of Economic Freedom & 61.8722 & 10.5502 & 21.4 & 8.97 & .6688 \\
\hline \hline
\end{tabular}


Table 3: Estimation of the Semiparametric Smooth Coefficient Stochastic Frontier

\begin{tabular}{|c|c|c|c|c|}
\hline \multicolumn{5}{|c|}{ Panel A: Economic Freedom of the World Index } \\
\hline MLE & Estimates & Standard Error & & \\
\hline$\hat{\sigma}_{u}^{2}$ & 2.0241 & .4566 & & \\
\hline$\hat{\sigma}_{v}^{2}$ & .0357 & .0037 & & \\
\hline$\hat{\eta}$ & -.1383 & .0132 & & \\
\hline Smooth Coefficient & Mean & 10th Percentile & Median & 90th Percentile \\
\hline$\hat{\alpha}(E F)$ & 2.0446 & 1.0160 & 2.0949 & 2.9463 \\
\hline$\hat{\beta}_{H}(E F)$ & .3374 & -.0307 & .1654 & .9552 \\
\hline$\hat{\beta}_{L}(E F)$ & .2184 & .1557 & .1911 & .3418 \\
\hline$\hat{\beta}_{K}(E F)$ & .7413 & .5922 & .7614 & .8467 \\
\hline \multicolumn{5}{|c|}{ Panel B: Index of Economic Freedom } \\
\hline MLE & Estimates & Standard Error & & \\
\hline$\hat{\sigma}_{u}^{2}$ & .2834 & .0373 & & \\
\hline$\hat{\sigma}_{v}^{2}$ & .0333 & .0027 & & \\
\hline$\hat{\eta}$ & -.0056 & .0017 & & \\
\hline Smooth Coefficient & Mean & 10th Percentile & Median & 90th Percentile \\
\hline$\hat{\alpha}(E F)$ & 2.0068 & 1.4956 & 1.9827 & 2.5315 \\
\hline$\hat{\beta}_{H}(E F)$ & .4299 & .1771 & .2922 & .6694 \\
\hline$\hat{\beta}_{L}(E F)$ & .2340 & .1767 & .2024 & .3712 \\
\hline$\hat{\beta}_{K}(E F)$ & .7344 & .6391 & .7606 & .7821 \\
\hline
\end{tabular}


Table 4: Maximum Likelihood Estimation of Parametric Benchmark Models

\begin{tabular}{|c|c|c|c|c|c|c|}
\hline \multicolumn{7}{|c|}{ Panel A: Economic Freedom of the World Index } \\
\hline \multirow{2}{*}{ Variables } & \multicolumn{2}{|c|}{ Cobb-Douglas Model } & \multicolumn{2}{|c|}{ Translog Model } & \multicolumn{2}{|c|}{ Restricted Translog Model } \\
\hline & Coefficient & Prob. & Coefficient & Prob. & Coefficient & Prob. \\
\hline Constant & 5.3703 & .0000 & 7.7710 & .0000 & 7.9271 & .0000 \\
\hline$E F$ & -.3178 & .0129 & -.1716 & .3067 & -.6367 & .0000 \\
\hline$E F^{2}$ & .0231 & .0080 & .0006 & .9490 & .0100 & .3059 \\
\hline $\operatorname{Ln}(H)$ & .6076 & .0000 & 4.5700 & .0000 & .6522 & .2167 \\
\hline $\operatorname{Ln}(L)$ & .3836 & .0000 & 1.2026 & .0000 & .4167 & .0002 \\
\hline $\operatorname{Ln}(K)$ & .5362 & .0000 & -.4002 & .1029 & .2678 & .0010 \\
\hline $\operatorname{Ln}^{2}(H)$ & - & - & 1.8076 & .0012 & - & - \\
\hline$L n^{2}(L)$ & - & - & .0830 & .0005 & - & - \\
\hline$L n^{2}(K)$ & - & - & .0731 & .0000 & - & - \\
\hline $\operatorname{EFLn}(H)$ & - & - & .1381 & .1480 & -.0368 & .6378 \\
\hline$E F L n(L)$ & - & - & .0216 & .3247 & -.0117 & .4696 \\
\hline $\operatorname{EFLn}(K)$ & - & - & .0051 & .7832 & .0443 & .0005 \\
\hline $\operatorname{Ln}(H) \operatorname{Ln}(L)$ & - & - & .6310 & .0000 & - & - \\
\hline $\operatorname{Ln}(H) \operatorname{Ln}(K)$ & - & - & -.7418 & .0000 & - & - \\
\hline $\operatorname{Ln}(L) \operatorname{Ln}(K)$ & - & - & -.1442 & .0000 & - & - \\
\hline$\hat{\sigma}_{u}^{2}$ & 2.6714 & .0234 & 2.8809 & .0539 & 3.2214 & .0170 \\
\hline$\hat{\sigma}_{v}^{2}$ & .0217 & .0000 & .0194 & .0000 & .0209 & .0000 \\
\hline$\hat{\eta}$ & -.1156 & .0013 & -.0519 & .1814 & -.0404 & .0000 \\
\hline Log-likelihood & & 359.065 & & 390.614 & & 372.628 \\
\hline Observations & & 440 & & 440 & & 440 \\
\hline \multicolumn{7}{|c|}{ Panel B: Index of Economic Freedom } \\
\hline \multirow{2}{*}{ Variables } & \multicolumn{2}{|c|}{ Cobb-Douglas Model } & \multicolumn{2}{|c|}{ Translog Model } & \multicolumn{2}{|c|}{ Restricted Translog Model } \\
\hline & Coefficient & Prob. & Coefficient & Prob. & Coefficient & Prob. \\
\hline Constant & 5.8476 & .0000 & 4.7966 & .0000 & 5.8135 & .0000 \\
\hline$E F$ & -.6265 & .0000 & -.4942 & .0072 & -.6271 & .0000 \\
\hline$E F^{2}$ & .0425 & .0000 & .0338 & .0164 & .0431 & .0024 \\
\hline $\operatorname{Ln}(H)$ & .5589 & .0000 & 2.9839 & .0045 & 1.8180 & .0028 \\
\hline $\operatorname{Ln}(L)$ & .3178 & .0000 & .4311 & .1707 & .2154 & .2017 \\
\hline $\operatorname{Ln}(K)$ & .5995 & .0000 & .4715 & .0937 & .5183 & .0000 \\
\hline $\operatorname{Ln}^{2}(H)$ & - & - & 1.6340 & .0027 & - & - \\
\hline $\operatorname{Ln}^{2}(L)$ & - & - & .0398 & .1067 & - & - \\
\hline$L n^{2}(K)$ & - & - & .0159 & .3942 & - & - \\
\hline$E F L n(H)$ & - & - & -.2100 & .0523 & -.1988 & .0354 \\
\hline$E F L n(L)$ & - & - & -.0121 & .6699 & -.0215 & .6194 \\
\hline$E F L n(K)$ & - & - & .0184 & .3723 & .0135 & .4237 \\
\hline $\operatorname{Ln}(H) \operatorname{Ln}(L)$ & - & - & .4007 & .0111 & - & - \\
\hline $\operatorname{Ln}(H) \operatorname{Ln}(K)$ & - & - & -.3676 & .0169 & - & - \\
\hline $\operatorname{Ln}(L) \operatorname{Ln}(K)$ & - & - & -.0402 & .2791 & - & - \\
\hline$\hat{\sigma}_{u}^{2}$ & 8.3085 & .0227 & 4.1121 & .1197 & 6.7571 & .0848 \\
\hline$\hat{\sigma}_{v}^{2}$ & .0214 & .0000 & .0209 & .0000 & .0212 & .0000 \\
\hline$\hat{\eta}$ & -.2292 & .0000 & -.1855 & .0003 & -.2165 & .0000 \\
\hline Log-likelihood & & 367.893 & & 380.418 & & 372.176 \\
\hline Observations & & 440 & & 440 & & 440 \\
\hline
\end{tabular}



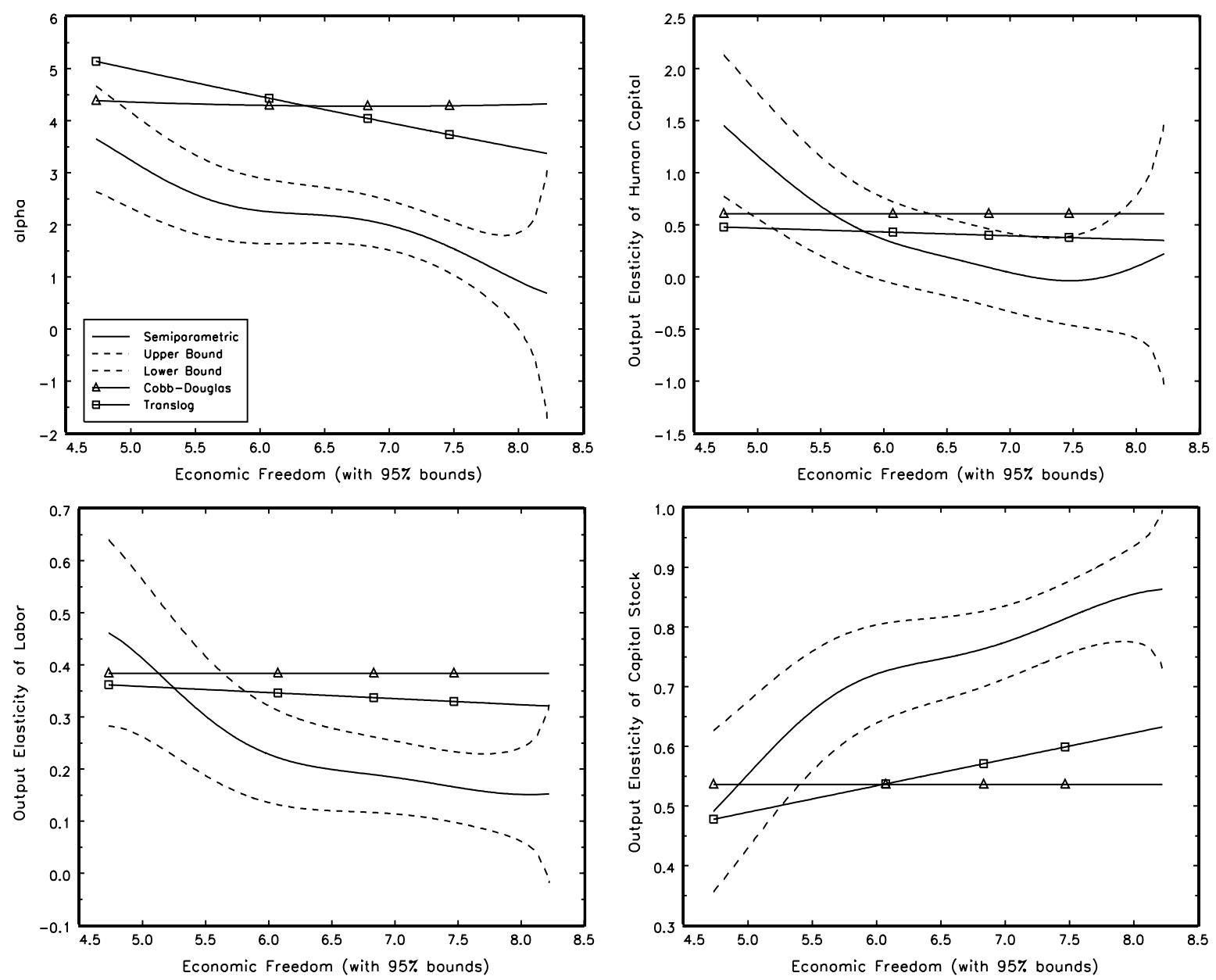

Figure 1: Plots of Smooth Coefficient Frontiers Against EFW
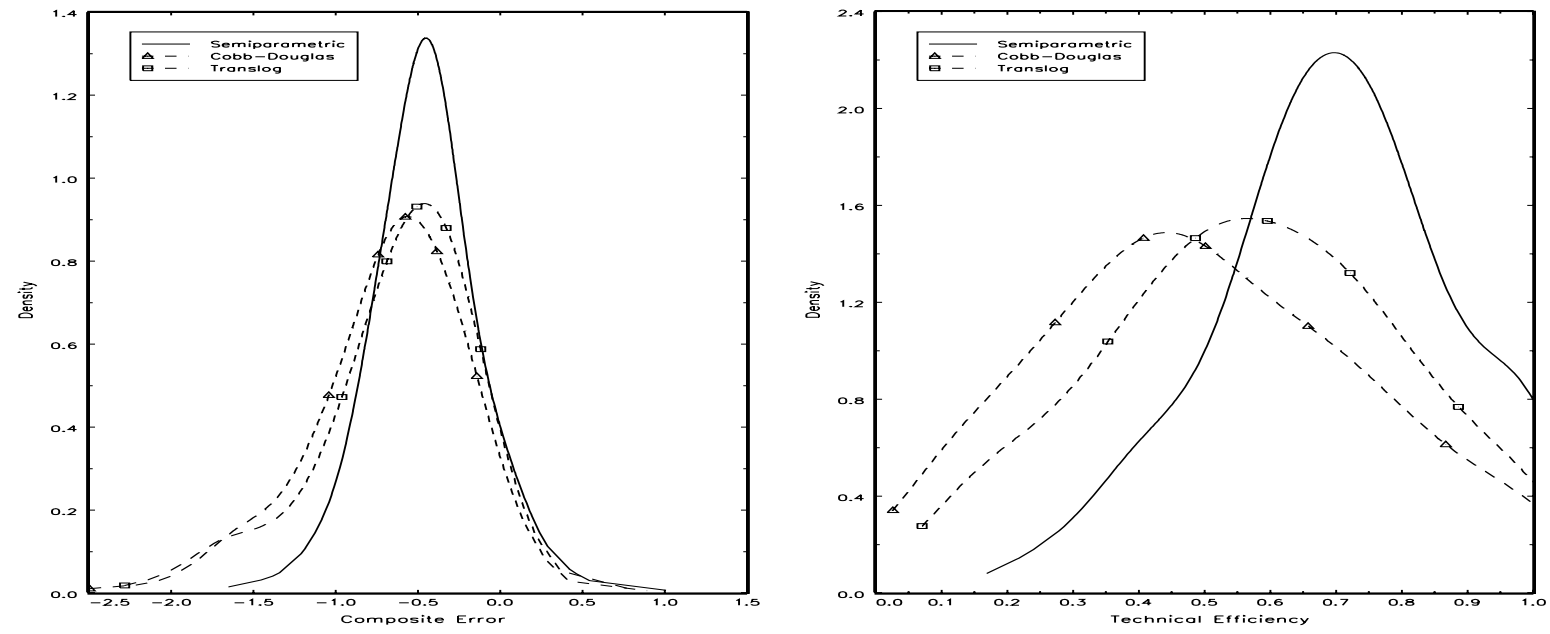

Figure 2: Kernel Density of Composite Error and Technical Efficiency EFW 

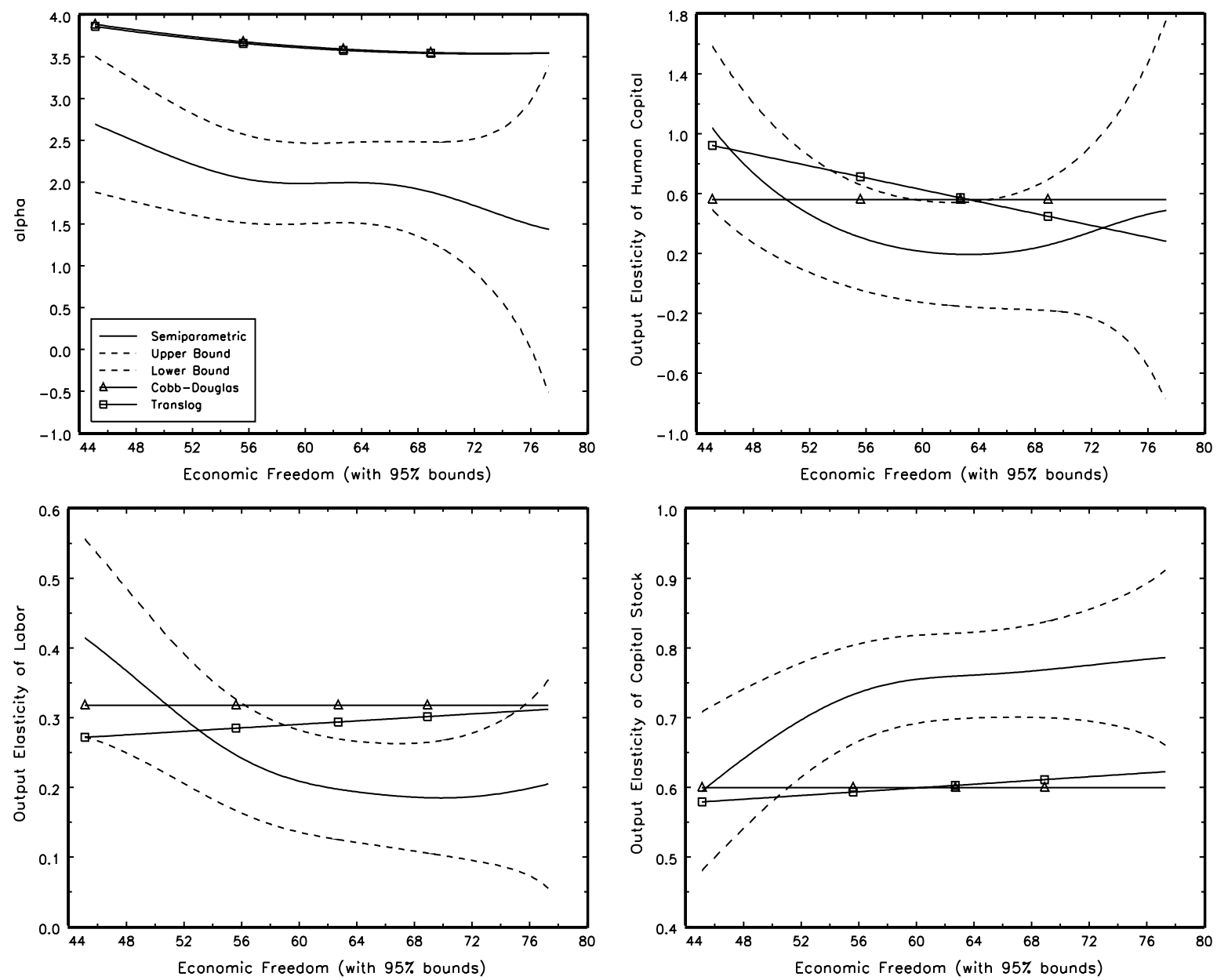

Figure 3: Plots of Smooth Coefficient Frontiers against Heritage index
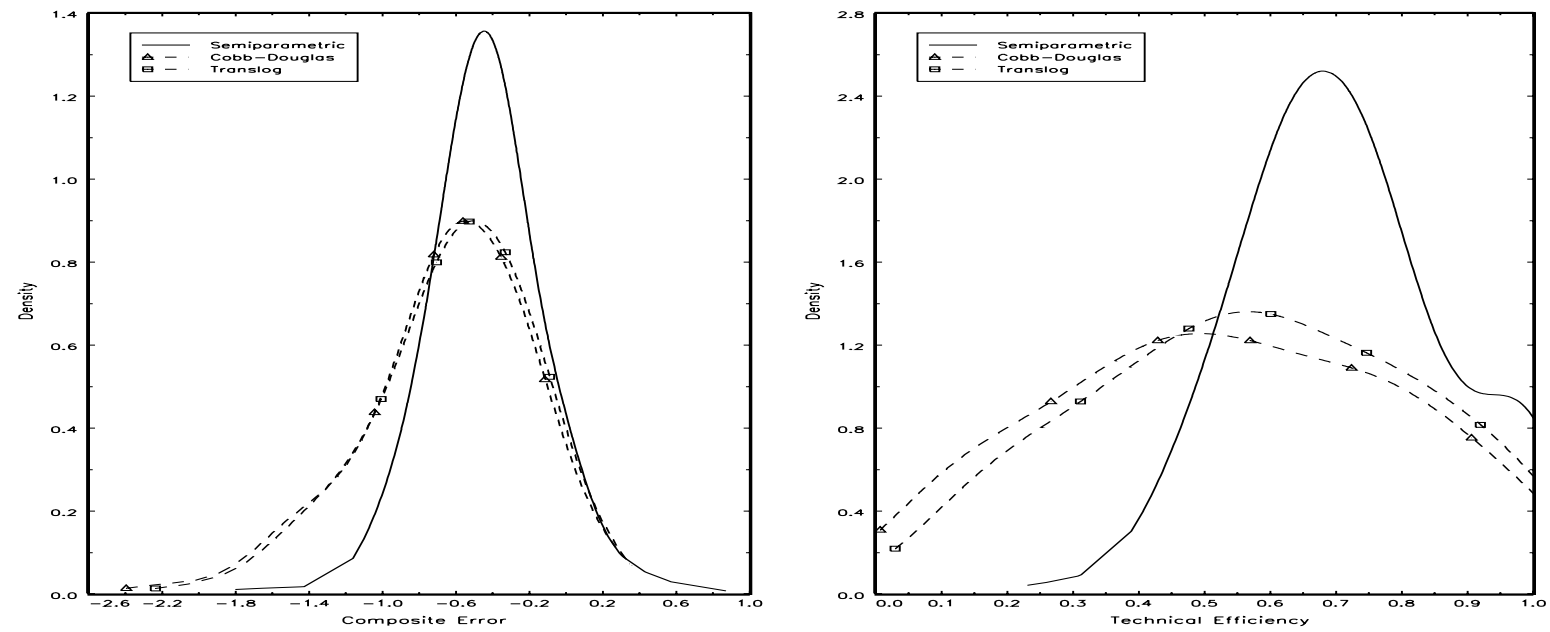

Figure 4: Kernel Density of Composite Error and Technical Efficiency Heritage index 

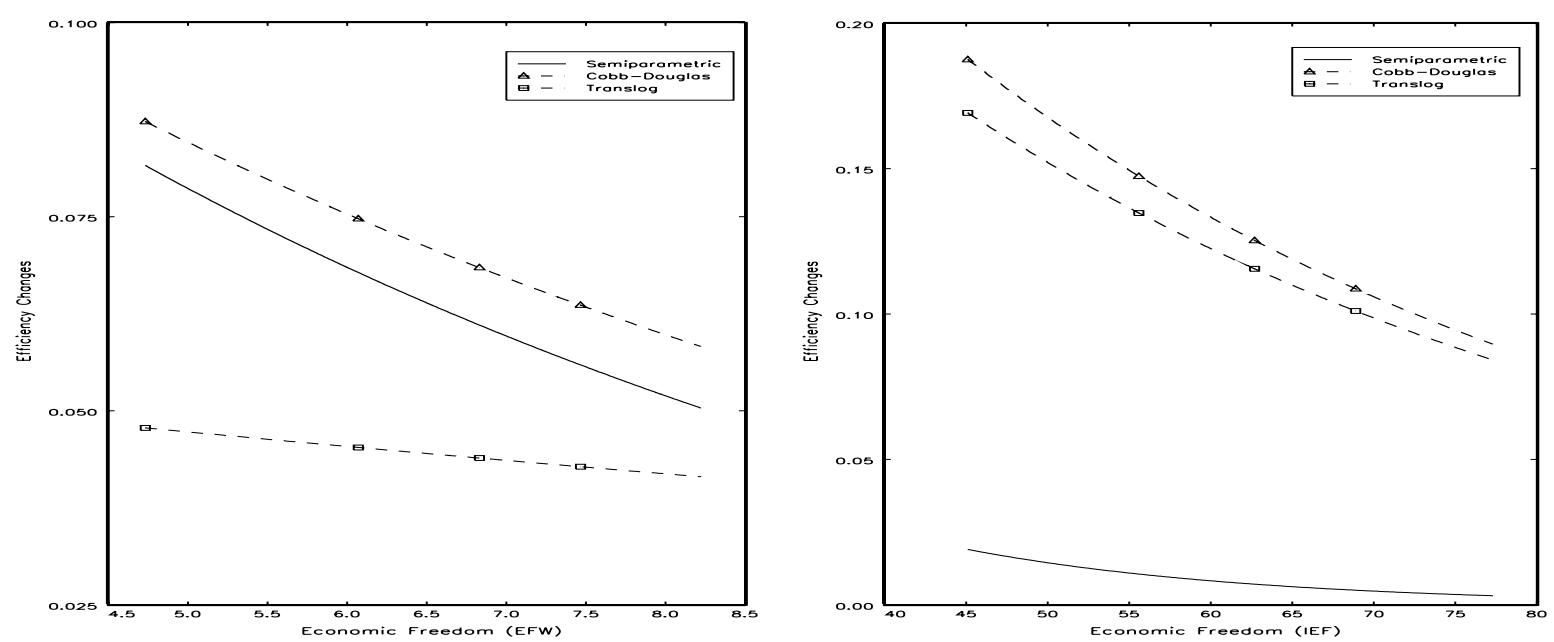

Figure 5: Partial Effect of Economic Freedom on Technical Efficiency 